\title{
ENZYMATIC INTERESTERIFICATION OF PALM FRACTIONS FOR THE PRODUCTION OF COCOA BUTTER ALTERNATIVES
}

\author{
NORAZURA AILA MOHD HASSIM*; NUR HAQIM ISMAIL* and NOOR LIDA HABI MAT DIAN*
}

\begin{abstract}
Cocoa butter is the most preferable confectionery fat. In spite of this, cocoa butter alternatives (CBA) are also highly sought-after confectionery fats due to low supply and higher cost of cocoa butter. In the pursuit to produce palm-based CBA, various technological modification techniques have been employed. These include fractionation, blending, hydrogenation, interesterification (chemical and interesterification) or combination of these processes. Enzymatic interesterification (EIE) of lipids has received a lot of attention for the production of palm-based CBA especially cocoa butter equivalent. This review article, therefore, intends to offer an overview of EIE studies for the production of palm-based CBA. In this review, technological modification techniques are discussed in brief while publication related to EIE are discussed in depth based on its reactions categories (i.e. acidolysis, ester-ester exchange and alcoholysis). Reaction condition (i.e. subtrate, enzyme and optimum condition) and outcome of the EIE process are outlaid in this article.
\end{abstract}

Keywords: cocoa butter alternatives (CBA), cocoa butter equivalent (CBE), enzymatic interesterification, palm fractions.

Date received: 8 January 2018; Sent for revision: 9 January 2018; Received in final form: 26 March 2018; Accepted: 5 July 2018.

\section{INTRODUCTION}

Cocoa butter is a preferable fat for the production of chocolate as it would be able to impart the desirable attributes and sensory properties of chocolate (Lipp et al., 2001). It comprises more than $50 \%$ saturated fatty acids (Borhan et al., 2011). The unique triacylglycerols (TAG) composition of cocoa butter having about 21\% 1,3-dipalmitoyl-2-oleoyl-glycerol (POP), 40\% 1,3-stearoyl-2-oleoyl-3,1-palmitoyl glycerol (POS) and 27\% 1,3-distearoyl-2-oleoylglycerol (SOS) contributes to its pleasant physical properties such as snap ability, glossiness, mouth feel and flavour release (Ozan et al., 2008; Shukla, 1995). Cocoa butter is solid and brittle at $20^{\circ} \mathrm{C}$ but is able to completely melt in mouth (Liu et al., 2007; Timms, 2003). Notwithstanding this, the supply of cocoa butter is uncertain which makes it a pricy raw

Malaysian Palm Oil Board

6 Persiaran Institusi, Bandar Baru Bangi,

43000 Kajang, Selangor, Malaysia.

E-mail: azuraaila@mpob.gov.my material (Norazura and Noor Lida, 2017; Tchobo et al., 2009; Abigor et al., 2003). This might be due to difficult cultivation, low productivity and pest attack (Lipp and Anklam, 1998).

Cocoa butter alternatives (CBA) derived from other vegetable fats is not a new term to chocolate manufacturers. Cocoa butter equivalent (CBE), cocoa butter replacer (CBR) and cocoa butter substitute (CBS) are the main CBA found in the market nowadays. Cocoa butter improver (CBI) and cocoa butter extender (CBX) are also common fats that fall under CBE category. However, their usage is limited. CBE possesses similar physico-chemical properties as cocoa butter and due to these properties, CBE has the advantage to be blended with cocoa butter at any percentage (full compatibility). CBR and CBS on the other hand, only possess similar physical properties with cocoa butter and thus have limited compatibility with cocoa butter.

The production of CBA from various sources of raw material has been discussed in many review papers (Naik and Kumar, 2014; Jahurul et al., 2013; Lipp and Anklam, 1998). This includes palm oil, 
palm kernel oil (PKO) and their fractions which have drawn immense research interest due to their potential as a source of CBA. In addition, production of CBA from palm oil, PKO and their fractions has been well reviewed by Norazura and Noor Lida (2017). Their paper revealed that CBE, CBR and CBS can be produced using various techniques including fractionation, blending, hydrogenation, chemical interesterification, enzymatic interesterification (EIE) or combination of any of these processes. These processes will be touched in brief in the next section to provide general ideas on various techniques for the production of CBA. This article aims to provide an update on scientific research on the usage of palm oil, palm kernel oil and their fractions for the production of enzymatically interesterified CBA. The scope of this article is characterisation of palmbased enzymatically interesterified CBA according to reactions, reaction condition and outcome of the process especially TAG composition.

\section{TYPES OF FAT MODIFICATION FOR THE PRODUCTION OF COCOA BUTTER ALTERNATIVES (CBA)}

Fractionation which is a thermo-mechanical separation process is common in oil palm industry to separate high melting fractions from low melting fractions. Three categories of fractionation currently available include dry fractionation, solvent fractionation and detergent fractionation (Kellens et al., 2007). In the oil palm industry, dry fractionation is the simplest, most cost-effective and natural (free from chemical, effluent and losses) fractional crystallisation method (Gibon, 2006). This technique can be performed up to the third fractionation stage producing hard palm mid fraction (HPMF) (MPOB, 2009) with iodine value (IV) of less than 36 (Kellens et al., 2007). HPMF is a suitable fat for making CBE (Ng and Gibon, 2010). Palm kernel stearin (PKOs) that is fractionated from PKO is able to function as lauric CBS. HPMF and PKOs are examples of fractionated products that can be directly used as CBA.

Blending technique on the other hand, becomes useful especially when it comes to producing CBE. Palm mid fraction (PMF) having IV of 40-50 (Sivaruby et al., 2013) obtained from the second fractionation of palm oil is rich in POP. It is normally blended with exotic fats such as illipe (rich in POS), shea (rich in SOS), kokum fat (rich in SOS), sal fat (rich in POS) and mango seed fat (rich in SOS) to produce CBE (Sonwai et al., 2014; Bootello et al., 2012; Talbot, 2007; Timms, 2003). For further example, blending has also been used in a study by Jahurul et al. (2014) to produce trans-free CBR. The study blended palm stearin with mango seed fat. Blending does not involve chemical modification, thus this is its plus point. However, it is always a trial and error process to achieve the suitable amount of oil (Wassell and Young, 2007).

Addition of hydrogen to unsaturated fatty acids having double bonds is called hydrogenation. Hydrogenation results to a greater degree of saturation which reflects higher TAG structure rigidity and higher melting point (Young et al., 1994). For example, PKO that has undergone full hydrogenation is able to function as CBS (Talbot, 2007). Contrary to full hydrogenation, partial hydrogenation produces trans isomers that contribute to adverse health effect (Iqbal, 2014; Mozaffarian et al., 2006).

Interesterification can be divided into two groups; chemical and enzymatic in which the fatty acids can be rearranged between or within the TAG (Noor Lida et al., 2002). Interesterification is often viewed as a substitute to hydrogenation (Dijkstra, 2015). EIE of lipids has received a lot of attention over chemical interesterification since the 1980s (Holm and Cowan, 2008). The purpose or objective of EIE is to alter the fatty acid composition which consequently affect the lipids physico-chemical, nutritional attributes and their functionality to fit certain applications especially in the food industry (Sellappan and Akoh, 2000). It has been viewed as a compelling tool for the oils and fats modification in order to achieve higher value products with structured TAG (Borhan et al., 2011; Xu, 2000a). This is primarily due to greater lipases specificity, minimal energy consumption, reduced development of byproducts and efficient control of products. The great availability of lipase also reduces operational costs of interesterification in general (Aravindan et al., 2007; Khumalo et al., 2002). It is possible to produce particular tailor-made TAG composition through EIE in which the overall EIE process is affected by acyl donor, reaction time and temperature, initial water activity, enzyme quality and substrate ratio. Most importantly, EIE has been approved to be used as methods of preparation for food products containing oils and fats as these lipases do not show any toxicity. Microbial lipases are preferred commercially compared to plant and animal lipases due to many factors such as availability, stability and production cost (Aravindan et al., 2007). Hasan et al. (2006) and Ghosh et al. (1996) have well reviewed the production and applications of microbial lipases.

EIE with non-regiospecific lipases produces similar end products as chemical interesterification which is randomised TAG composition. Randomised TAG composition is less useful when specific types of TAG composition that meet certain applications is desired. EIE with $s n-1,3$ regiospecific lipase on the other hand, is very attractive for the production of $\mathrm{CBE}$. This is due to the regiospecific interchange of acyl groups at $s n-1$ and $s n-3$ positions of the TAG, 
which results in the fatty acid at $s n-2$ position that remains unaffected (Esteban et al., 2011) as well as due to its thermostability (Undurraga, 2001). This regiospecific lipase is usually applied for producing functional lipids including $\mathrm{CBE}$ other than fats with low calorie and milk substitutes (Gibon, 2011). Unmodified lipids having oleic at the $s n-2$ position are at advantage as oleic fatty acid is one of the major fatty acids at the $s n-2$ position in cocoa butter TAG too (Talbot, 1999). Cho and Rhee (1993) had assessed eight commercial sn-1,3 regiospecific lipases to determine their suitability for the EIE process in general. In addition, immobilised lipases are always the preferred choice. It can be used repeatedly and can be physically removed from end product. This provides an avenue for economical and continuous processing set-up (Choo and Rhee, 1993; Bloomer et al., 1990). There are three commonly used enzymatic methods based on the types of reactions; acidolysis, ester-ester exchange and alcoholysis (De Clercq et al., 2012).

Palm oil and its fraction has the potential to be utilised as raw materials for EIE-based specialty products. Based on literature review that will be elaborated further in the next section, palm oil, palm olein and PMF are amongst the most used fractions when embarking into EIE method to produce CBA. Among these fractions, PMF has been the centre of attraction for the EIE method and this might be due to high source of POP TAG. PMF is obtained through double fractionation of palm oil having iodine value (IV) of about $40.91 \pm 0.20$ to $49.50 \pm 0.13$ (Sivaruby, 2013). Typical attributes of Malaysian PMF is shown in Table 1.

\section{ENZYMATIC INTERESTERIFICATION FOR THE PRODUCTION OF COCOA BUTTER ALTERNATIVES}

\section{Acidolysis}

Enzymatic acidolysis is commonly used in the modification of oils and fats to produce CBE. It is a reversible reaction until equilibrium is reached $(\mathrm{Xu}, 2003)$. Typical enzymatic acidolysis reaction is shown in Figure 1a. In order to produce CBE, reaction between TAG and fatty acid takes place as shown in Figure 1b. The free fatty acid will replace the fatty acid in the TAG. Yield of the product depends on the ratio between TAG and fatty acid under equilibrium condition (substrate ratio) (Xu et al., 1998). Various factors must be considered (i.e. reaction time, reaction temperature, enzyme level, substrate ratio and water content) for the reaction to reach equilibrium $(\mathrm{Xu}, 2000 \mathrm{~b})$. However, enzymatic acidolysis will still produce by-products in terms of released fatty acid which can be further removed as

TABLE 1. TYPICAL ATTRIBUTES OF PALM MID FRACTION

\begin{tabular}{lc}
\hline \multicolumn{1}{c}{ Attributes } & Value \\
\hline Iodine value $\left(\mathrm{I}_{2} / 100 \mathrm{~g}\right)$ & $40.91 \pm 0.20-49.50 \pm 0.13$ \\
Fatty acid composition (weight as methyl esters) & \\
C16:0 & $45.89 \pm 0.06-51.55 \pm 0.41$ \\
C18:0 & $4.52 \pm 0.01-5.17 \pm 0.04$ \\
C18:1 & $33.57 \pm 0.63-38.88 \pm 0.05$ \\
C18:2 & $6.13 \pm 0.02-8.64 \pm 0.00$ \\
Triacylglycerol composition (\% by weight.) & $0.69 \pm 0.04-2.57 \pm 0.04$ \\
PPP & $43.53 \pm 0.19-55.95 \pm 0.10$ \\
POP & $7.73 \pm 0.10-10.46-0.01$ \\
POS & \\
\hline Note: PPP - tripalmitoyl glycerol. & \\
POP - 1,3-dipalmitoyl-2-oleoyl glycerol. & \\
POS - 1,3-stearoyl-2-oleoyl-3,1-palmitoyl glycerol. & \\
Source: Sivaruby et al. (2013). &
\end{tabular}

i)

ii)

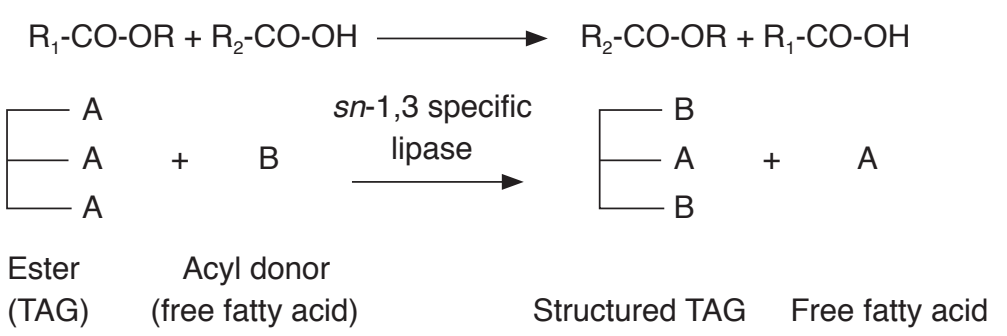

Source: iLee and Akoh (1998); iiXu (2003).

Figure 1. General enzymatic acidolysis reaction. 
shown in Steps 2 and 3 of Figure 2. Diacylglycerols (DAG) and monoacylglycerols (MAG) can also replace TAG to be used as ester (Naessens, 2012) in which it can produce side reactions and eventually by-products (Pancheco et al., 2010). Low level of water content is preferred in this reaction to avoid hydrolysis. Free fatty acids are broadly used as acyl donors presently as they are low in price, easy to get and have high reactivity (Xu, 2003). For CBE's production, stearic acid has been used extensively.

General flow chart for direct usage of interesterified $\mathrm{CBE}$ is shown in Figure 2. Based on the flow chart, POP fat such as PMF and palm olein is modified into 'POP/POS/SOS' fat by mimicking the TAG of cocoa butter through acidolysis reaction. The 'POP / POS / SOS' fat produced from EIE process (using sn-1,3 regiospecific enzyme as catalyst and acyl donor) is then subjected to stripping process to strip off excess acyl donor and further fractionation before the interesterified $\mathrm{CBE}$ can be utilised in confectionery (Gibon et al., 2009). Most researches concentrate until Step 1 of Figure 2 only without further discussing stripping and fractionation process.

Mojovic et al. (1993) used PMF with 90\% purity stearic acid as substrate to produce CBE through acidolysis reaction. The study utilised celite-immobilised sn-1,3 regiospecific Rhizopus arrhizus lipase as a catalyst and water-saturated n-hexane as solvent due to its low level of polarity and low denaturing side effect to the enzyme. The reaction was carried out in a batch reactor at $37^{\circ} \mathrm{C}$ and operated under 130 strokes $\min ^{-1}$ of shaking condition. Under the optimum condition (0.1 $\mathrm{ml}$ water $\mathrm{g}^{-1}$ of immobilised enzyme, 12-14 hr equilibrium time and 120 IU of immobilised enzyme $\mathrm{g}^{-1}$ of PMF), the interesterified product from this reaction yielded FAC composition of $23.4 \%$ palmitic fatty acid, $35.4 \%$ stearic fatty acid, 34\% oleic fatty acid and $6.5 \%$ linoleic fatty acid which is comparable with the FAC composition of cocoa butter. The author in 1994 proceeded with similar acidolysis reaction as conducted in 1993 using similar substrate and catalyst. However, in 1994, the reaction was conducted in a gas-lift reactor. The study found that equilibrium time in the gas-lift reactor is faster $(9 \mathrm{hr})$ compared to the batch reactor (12 hr). FAC composition of the interesterified fat in the gas-lift reactor was found to be comparable with the batch reactor. The productivity of using gas-lift reaction increased 2.8 times compared to the batch reactor (Mojovic et al., 1994).

PMF has also been used in a study by Undurraga et al. (2001) with stearic acid (99\% purity) as substrate through acidolysis reaction to produce enzymatic interesterified CBE. In their study, immobilised $s n-1,3$ regiospecific Novo Lypozyme lipase was used as catalyst in a solvent free environment. For food application, solvent free processes/system is always preferred. Batch and continuous packed bed reactors were used to conduct the experiments. The TAG composition of the interesterified CBE is shown in Table 2. The interesterified CBE has TAG composition that was quite comparable to cocoa butter especially the POP composition. However, this $\mathrm{CBE}$ contains diglycerides which needs further purification process. Diglycerides may affect the CBE's fusion attribute.

Biswas et al. (2018) enzymatically interesterified $80 \%$ palm-based ternary blend (33.3\% PMF, 33.3\% PKO and $33.3 \%$ palm stearin) with $15 \%$ stearic acid and $5 \%$ oleic acid using $4 \%(\mathrm{w} / \mathrm{w})$ immobilised sn-1,3 regiospecific Thermomyces lanuginose lipase (Lypozyme TLIM) to produce CBS via acidolysis reaction. The reaction was carried out for $6 \mathrm{hr}$

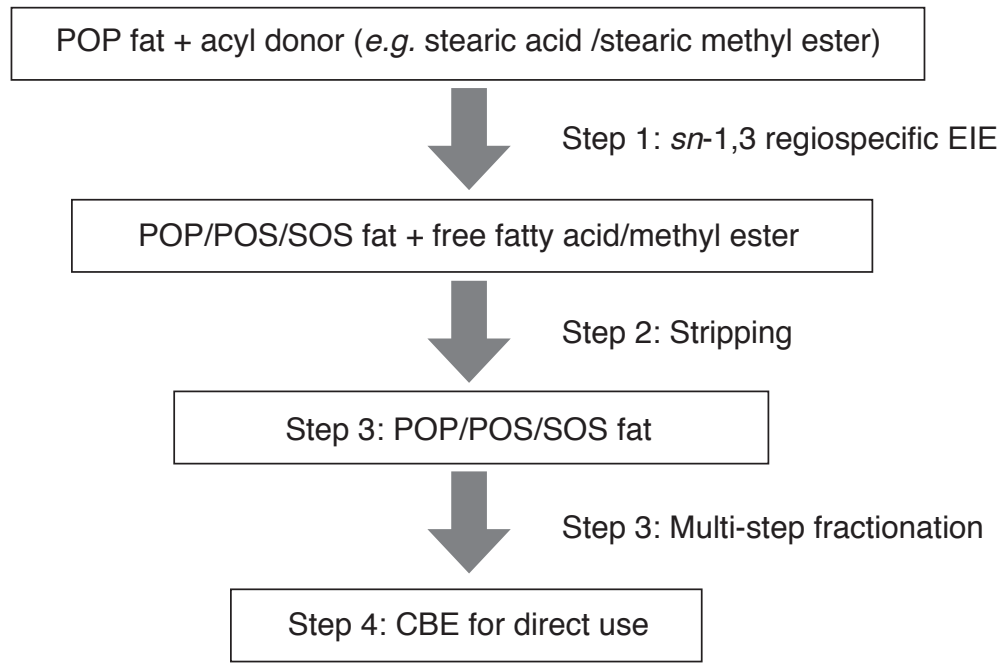

Source: Gibon et al. (2009).

Figure 2. General flow chart for the production of cocoa butter equivalent (CBE) through acidolysis reaction. 
TABLE 2. TRIACYLGLYCEROL (TAG) COMPOSITION OF PALM MID FRACTION (PMF), COCOA BUTTER (CB) AND INTERESTERIFIED COCOA BUTTER EQUIVALENT (CBE)

\begin{tabular}{lccccc}
\hline Sample & POP $(\%)$ & POS $(\%)$ & SOS $(\%)$ & Other TAG $(\%)$ & DAG $(\%)$ \\
\hline PMF & 74.3 & 14.3 & 2.0 & 9.4 & - \\
CB & 23.4 & 42.8 & 27.5 & 3.6 & 2.7 \\
Interesterified CBE & 23.4 & 38.5 & 20.2 & 8.2 & 9.7 \\
\hline
\end{tabular}

Note: POP - 1,3-dipalmitoyl-2-oleoyl glycerol.

POS - 1,3-stearoyl-2-oleoyl-3,1-palmitoyl glycerol.

SOS - 1,3-distearoyl-2-oleoyl glycerol.

Source: Undurraga et al. (2001).

at $60^{\circ} \mathrm{C}$ and shook at the speed of $250 \mathrm{rpm}$. The interesterified CBS showed good melting endotherm as cocoa butter at $33.5^{\circ} \mathrm{C}$ having TAG composition of $28.4 \%$ POS, $19.5 \%$ SOS and $17.7 \%$ POP. However, the interesterified CBS has different SFC value and polymorphism with cocoa butter. Notwithstanding this, it still could have the potential to be used as CBS. In addition, $5 \%-20 \%$ of this interesterified CBS can potentially be added to cocoa butter without significantly modifying its physico-chemical properties.

Palm fatty acid distillate (PFAD) together with PMF have been utilised to produce enzymatically interesterified CBE using immobilised $s n-1,3$ regiospecific Rhizomucor miehei lipase (Lipozyme IM) through acidolysis reaction (Ibrahim, 2013). PFAD is a by-product of palm oil refining process. In the study, the PFAD mixture contains 57.0\% stearic fatty acid, $40.0 \%$ palmitic fatty acid and $1.5 \%$ myristic fatty acid. The reaction was conducted in a batch reactor with n-hexane solvent at $60^{\circ} \mathrm{C}$ (marginally above the melting point of the fatty acid mixture) and shook at the speed of $160 \mathrm{rpm}$. The study had compared different PMF:PFAD ratio and reaction time. It was found that PFAD:PMF in the ratio of 2:1 at $3 \mathrm{hr}$ reaction time, resulted to an interesterified CBE with TAG composition of 30.7\% POP, $40.1 \%$ POS, 9.0\% POO (1-palmitoyl-2,3-dioleoyl glycerol),
14.5\% SOS and 5.7\% SOO (1-stearoyl-2,3-dioleoyl glycerol). This ratio provided interesterified $\mathrm{CBE}$ having melting point of between $31.6^{\circ} \mathrm{C}-40.4^{\circ} \mathrm{C}$. Prior to the above study, the author has embarked on an IE study involving PFAD and palm olein (obtained through first fractionation of palm oil) by applying similar methodology as above. PFAD of the study consisted of 50\%-58\% stearic acid with 40\%-49\% palmitic acid. The study found that PFAD and palm olein in the ratio of 3:1 with reaction time of $3 \mathrm{hr}$ produced CBE with TAG composition of $26.6 \%$ POP, $42.1 \%$ POS, $7.5 \%$ POO, $18.0 \%$ SOS and $5.8 \%$ SOO. The melting temperature for this ratio is between $34.7^{\circ} \mathrm{C}-39.6^{\circ} \mathrm{C}$ (Ibrahim, 2012). More amount of PFAD is needed for the reaction with palm olein compared to PMF (Ibrahim, 2013). Based on both studies, PFAD could be used as raw material to create high value-added product, in this case CBE.

Gibon (2011) readjusted the POP/POS/SOS content of PMF with stearic acid (acyl donor) using immobilised Lipozyme Rhizomucor miehei lipase as catalyst through acidolysis reaction. At reaction time of $32 \mathrm{hr}$, composition of POS and SOS increased extensively from conversion of POP. The highest conversion of POS (31\%) and SOS (17\%) had occurred at soft PMF and stearic acid ratio of 25:75 at $32 \mathrm{hr}$ reaction time (Table 3 ).

TABLE 3. TRIACYLGLYCEROL (TAG) COMPOSITION OF COCOA BUTTER (CB), PALM MID FRACTION (PMF), STEARIC ACID AND INTERESTERIFIED COCOA BUTTER EQUIVALENT (CBE) AT $32 \mathrm{hr}$ REACTION TIME

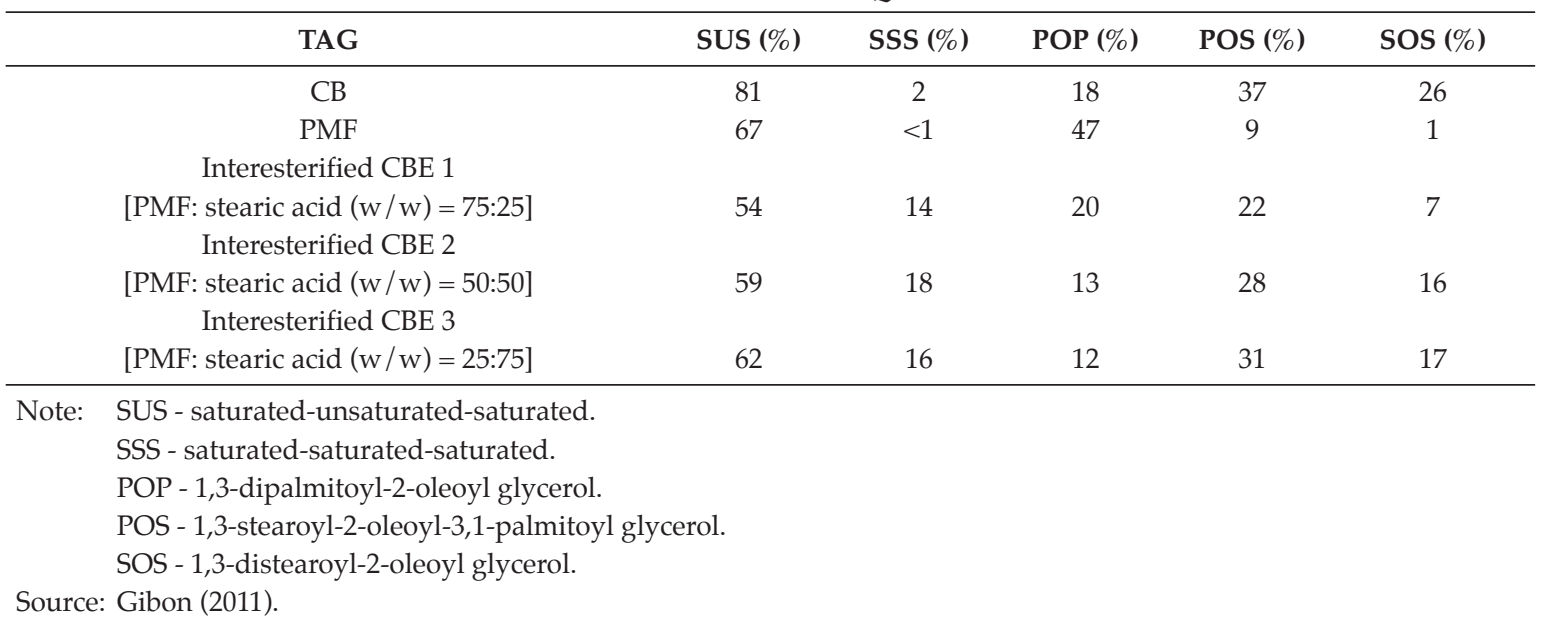


Enzymatic acidolysis reaction was also reported to be applied by Mutia et al. (2016) to formulate high nutritional CBE. The reaction was conducted between hard PMF and canola oil blend with stearic acid using an immobilised $s n-1,3$ regiospecific Lipozyme lipase. Hard PMF is exploited in the study as it is rich in SUS (saturated-unsaturated-saturated) TAG (Braipson-Danthine and Gibon, 2007) especially POP. Canola oil, on the other hand is low in SUS TAG but contains high UUU (unsaturatedunsaturated-unsaturated) TAG having balanced linoleic and linolenic acid (Prsybylski et al., 2005). The conditions to achieve optimised SUS TAGS of $64.44 \pm 1.18 \%$ was $89.0 \%$ weight of HPMF, $5 \%$ (based on substrate's weight) enzyme load and reaction time of 2 hr. Composition of the SUS TAG was not mentioned in the study. Linoleic and linolenic acids in the CBE after interesterification were $4.53 \pm 0.06 \%$ and $0.74 \pm 0.14 \%$, respetively. Fatty acid before and after the reaction showed no significant different especially for the linoleic and linolenic acids (Mutia et al., 2016).

Chong et al. (1992) enzymatically interesterified palm olein and palm-based stearic acid (98.3\% purity) using immobilised sn-1,3-regiospecific Novo Lipozyme lipase as catalyst through acidolysis reaction. The reaction was carried out at $60^{\circ} \mathrm{C}$ for $20 \mathrm{hr}$ with mechanical stirring of $200 \mathrm{rpm}$. Ten percent Lipozyme catalyst was used per weight of oil with $1 \%$ of water (volume) per weight of oil. The study also compared three types of further solvent fractionation processes using hexane, acetone and hexane-acetone. CBE obtained after the hexane solvent fractionation produced $89.0 \%$ SUS TAG (15.3\% POP, $44.1 \%$ POS and $29.6 \%$ SOS) which is comparable with SUS TAG of cocoa butter $(89.9 \%)$. The CBE has melting profile of between $30.4^{\circ} \mathrm{C}-38.9^{\circ} \mathrm{C}$. However, $\mathrm{CBE}$ obtained after the hexane-acetone and acetone solvent fractionation yielded lower SUS TAG with content around 78\%. Therefore, palm olein is a good feedstock to produce cocoa butter-like TAG. As most EIE researches focused on obtaining CBE having similar TAG as cocoa butter, Chong et al. (1992) further processed the interesterified CBE for direct use.

A patent by Kang et al. (2011) revealed that CBE having $85 \%$ SOS can be produced through EIE by acidolysis reaction. Oil blend for the reaction's substrate includes combination of two or more oils from various oils and fats sources amongst others are palm oil, palm stearin, $\mathrm{PKO}$ and palm kernel olein. The sn-1,3 regiospecific Thermomyces lanuginose lipase (Lipozyme TLIM) is used as catalyst. The ratio for the substrate oil and acyl donor (stearic acid) is between 1:2 to 1:6 with water content below $0.02 \%$ and reaction time of between $40^{\circ} \mathrm{C}-50^{\circ} \mathrm{C}$. The CBE has solid fat content (SFC) of between $40 \%-45 \%$ SFC at $20^{\circ} \mathrm{C}$ and $0 \%-0.5 \%$ at $35^{\circ} \mathrm{C}$.

\section{Ester-ester Exchange}

A reaction between two esters (two TAG) is referred to as ester-ester exchange (Figure 3). A reaction of TAG and fatty acid ethyl esters which mimic the enzymatic acidolysis process is also considered as ester-ester exchange. Similar to enzymatic acidolysis, enzymatic ester-ester exchange is a reversible reaction until equilibrium is reached. Contrary to the enzymatic acidolysis reaction, ideally the enzymatic ester-ester exchange does not produce any by-product (Xu, 2003).

Soekopitojo et al. (2009) interesterified fat blends of PMF (rich in POP) and fully hydrogenated soyabean oil (FHSO) (rich in stearic acid) by using an immobilised sn-1,3 regiospecific Lipozyme TLIM catalyst to produce CBE through esterester exchange reaction. The reaction process was conducted in $200 \mathrm{rpm}$ shaking condition at $68^{\circ} \mathrm{C}-70^{\circ} \mathrm{C}$ with reaction time of $4 \mathrm{hr}$ and $6 \%$ enzyme load. The interesterified product then underwent solvent fractionation process (hexane and acetone) to produce direct use CBE. Substrate ratio of 1:2 of PMF:FHSO was found to have comparable desired TAG composition of POS (37.7\%) and SOS (26.0\%). Howeves, it resulted to low POP $(9.5 \%)$ compared to cocoa butter. The fractionation alters the SFC of the $\mathrm{CBE}$ which makes it less comparable to cocoa butter. $\mathrm{SMP}$ of the final $\mathrm{CBE}$ range between $31.8^{\circ} \mathrm{C}-33.4^{\circ} \mathrm{C}$ with yield of about 20.5\% (based on substrate's original weight).

In addition, Wu and Deng (2005) too had produced $\mathrm{CBE}$ through similar reaction of $\mathrm{PMF}$ and stearic acid methyl ester (SAME) using sn1,3 regiospecific immobilised Lipozyme lipase as catalyst. The process is conducted in a solvent free environment/system. The study found that reaction temperature of $55^{\circ} \mathrm{C}$ with shaking speed of $150 \mathrm{rpm}$ and initial lipase catalyst to substrate ratio of $300 \mathrm{U} / 10 \mathrm{~g}$ with initial acyl donor (SAME) to PMF of one is the ideal processing condition of the interesterified CBE.

Abigor et al. (2003) on the other hand, interesterified palm oil (rich in palmitic acid and oleic acid) with hydrogenated soyabean oil (HSO) (rich in stearic acid) for the production of CBE through ester-ester exchange reaction (Figure 3). Sn1,3 regiospecific immobilised Lipozyme Rhizomucor miehei lipase was used as a catalyst and the reaction was carried out at $70^{\circ} \mathrm{C}$ with $4 \mathrm{hr}$ reaction time and $10 \%$ (by weight) enzyme load. The reaction was magnetically stirred at $200 \mathrm{rpm}$. The interesterified CBE was then further fractionated using acetone. The study found that at the ratio of $1.6: 1$ of palm oil: HSO, the yield of the CBE was $45 \%$ of original substrate's weight. Without further acetone purification process, the interesterified CBE contains considerable level of DAG which may jeopardise its possibility to be utilised as confectionery fat. The 


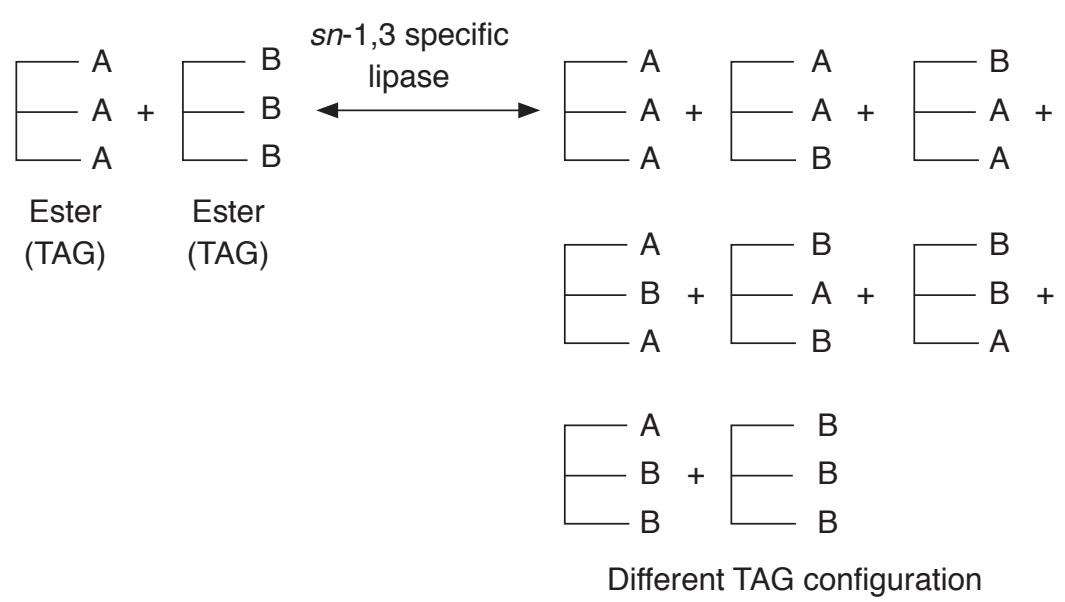

Source: Xu (2003)

Figure 3. General enzymatic ester-ester exchange reaction.

purified CBE contains TAG which are comparable to cocoa butter with melting point of $33.8^{\circ} \mathrm{C}$.

Another ester-ester exchange example is the EIE of palm oil and tristearin using five different lipases; Aspergillus niger, Candida cylindracea type VII, Mucor miehei, Penicillium camembertii and Pseudomonas cepacia as catalyst. The optimum reaction conditions were when immobilised Rhizomucor miehei lipase was used with $50^{\circ} \mathrm{C}$ reaction temperature, 10342.14 $\mathrm{kPa}(1500 \mathrm{psi})$ reaction pressure, 60:0.06 ratio of palm oil:tristearin, $5 \%$ ( $\mathrm{vol} / \mathrm{vol})$ of water content, supercritical carbon dioxide reaction medium, 5714:9:1 ratio for mixed co-solvent of supercritical carbon dioxide:hexane:t-butyl alcohol and $\mathrm{pH} 7$ of the aqueous solution. The yield of the purified CBE is $53.0 \%$ while its melting point is $34.3^{\circ} \mathrm{C}$ (Liu et al., 1997).

Pinyaphong and Phutrakul (2009) on the other hand, enzymatically interesterified palm oil with three types of acyl donor namely methyl stearate, ethyl stearate and stearic acid with Carica papaya lipase (papaya latex) through ester-ester exchange reaction. The lipase which is plant-based is known to have $s n-1,3$ regiospecificity (Villeneuve et al., 1997). In their study, it was found that the optimum ratio of 1.3:1 of stearic acid and palmitic acid was obtained from the reaction of palm oil and methyl stearate under the following condition: $45^{\circ} \mathrm{C}$ reaction temperature, $4 \mathrm{hr}$ reaction time, 0.11 initial water activity, 18 weight $\%$ of enzyme quantity and substrate ratio of $1 \mathrm{~mol}$ palm oil: $4 \mathrm{~mol}$ methyl stearate. The CBE yield was 55\% (based on palm oil usage) under optimum condition. The interesterified CBE as shown in Table 4 has comparable physicochemical as cocoa butter except for acid value.
Apart from producing $\mathrm{CBE}$, enzymatic esterester exchange can be applied to produce CBS. Borhan et al. (2011) produced low-calorie CBS by interesterifying PMF, PKOs and medium chain triglicerides (MCT) using an immobilised sn-1,3 regiospecific Rhizomucor miehei lipase as catalyst. MCT is an effective energy source as it metabolises faster compared to long-chain triacylglycerols (LCT). Therefore, introduction of MCT to LCT can produce fats having quick energy source (Akoh and Yee, 1997). The interesterified CBS has TAG composition of $27.1 \%$ MCT, 57.1\% POP, 6.6\% POS and $0.4 \%$ PPP which resulted in melting point of $31^{\circ} \mathrm{C}$ with lower SFC at all temperatures compared to the its original fats. The physical property of the CBS is comparable to cocoa butter but slightly softer (Borhan et al., 2011).

\section{Alcoholysis}

Interaction of an ester (e.g. TAG) and an alcohol (e.g. methanol, ethanol or glycerol) in the presence of lipase is called alcoholysis in which it is a reversible reaction $(\mathrm{Xu}, 2003)$. Figure 4 illustrates the enzymatic alcoholysis reaction. Alcoholysis is the least common reaction for the production of CBA. There is no research found that described this reaction for the production of palm-based CBA. However, Nazaruddin et al. (2011) might use palmbased commercial CBS, medium-chain fatty acid (MCFA); caprylic and capric acids and ethanol with $10 \%$ immobilised $s n-1,3$ regiospecific Thermomyces lanuginosus (TLIM) lipase as catalyst to produce a low-calorie confectionery fat through enzymatic alcoholysis reaction. The reaction was conducted

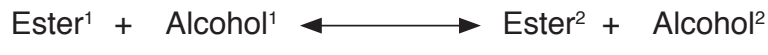

Source: Xu (2003). 
TABLE 4. PHYSICO-CHEMICAL ATTRIBUTES OF THE INTERESTERIFIED COCOA BUTTER EQUIVALENT

\begin{tabular}{lcc}
\hline Properties & Cocoa butter & Cocoa butter equivalent \\
\hline Melting point $\left({ }^{\circ} \mathrm{C}\right)$ & $35-39$ & $37-39$ \\
Iodine value $(\mathrm{g} / 100 \mathrm{~g})$ & 40.2 & 44.9 \\
Saponification value $\left(\mathrm{mg} \mathrm{g}^{-1}\right)$ & 190.7 & 193.2 \\
Acid value $(\%$ as palmitic acid) & 1.2 & 9.8 \\
\hline
\end{tabular}

Source: Pinyaphong and Phutrakul (2009).

in water bath at temperature of $50^{\circ} \mathrm{C}$ for $24 \mathrm{hr}$ with rotation speed of $250 \mathrm{rpm}$. Melting point of the lowcalorie fat after the reaction of enzymatic alcoholysis with caprylic acid was $26.19 \pm 2.46^{\circ} \mathrm{C}$ while with capric acid was $27.66 \pm 1.25^{\circ} \mathrm{C}$. Therefore, palmbased commercial CBS might be a potential substrate for the production of low-calorie confectionery fat. However, optimum conditions for this reaction has yet to be determined.

\section{CONCLUSION}

EIE has received considerable attention for the production of CBA especially CBE. Palm fractions namely palm oil, palm olein, PMF and PKOs are found to be used widely as feedstocks for EIEbased specialty products. Among these fractions, PMF has been the centre of attraction and has been used frequently in most studies discussed due to its high source of POP TAG. In addition, PFAD (palm oil refining by-product) has been able to increase its functionality to be used as feedstock in the production of high value-added confectionery product. It was found that acidolysis reaction was greatly used in EIE palm-based CBA compared to ester-ester exchange and alcoholysis. Although EIE palm-based specialty fat has the potential to be explored commercially, more research need to be conducted in obtaining exact physico-chemical specification of cocoa butter to compensate the growing demand of CBA due to expensive cocoa butter price, uncertain supply and technological reasons.

\section{ACKNOWLEDGEMENT}

The authors would like to thank the Director-General of MPOB for permission to publish this article.

\section{REFERENCES}

ABIGOR, R D; MARMER, W N; FOGLIA, T A; JONES, K C; DICICCIO, R J; ASHBY, R and UADIA, P O (2003). Production of cocoa butter-like fats by the lipase-catalyzed interesterification of palm oil and hydrogenated soybean oil. J. Amer. Oil. Chem. Soc. Vol. 80 (12): 1193-1196.

AKOH, C C and YEE, L N (1997). Enzymatic synthesis of position-specific low-calories structured lipids. $J$. Amer. Oil. Chem. Soc. Vol. 74: 1409-1413.

ARAVINDAN, R; ANBUMATHI, $\mathrm{P}$ and VIRUTHAGIRI, T (2007). Lipase applications in food industry. Indian J. Biotechnology Vol. 6: 141-158.

BISWAS, N; CHEOW, Y L; TAN, C P and SIOW, L F (2018). Physicochemical properties of enzymatically produced palm-oil-based cocoa butter substitutes (CBS) with cocoa butter mixture. Eur. J. Lipid Sci. Technol., 1700205: 1-9.

BLOOMER, S; ADLERCREUTZ, $\mathrm{P}$ and MATTIASSON, B (1990). Triglyceride interesterification by lipases. 1. Cocoa butter equivalents from a fraction of palm oil. J. Amer. Oil. Chem. Soc. Vol. 67 (8): 519-524.

BOOTELLO, M A; HARTEL, $\mathrm{R}$ W; GARCES, R; MATÍNEZ-FORCE, E and SALAS, J J (2012). Evaluation of high oleic-high steric sunflower hard stearins for cocoa butter equivalent formulation. Food Chemistry, 134: 1409-1417.

BORHAN, R-H; SAID, M and MAT SAHRI, M (2011). Enzymatic interesterification of palm products for producing low calorie cocoa butter substitutes. J. Applied Science, 11 (22): 3750-3754.

BRAIPSON-DANTHINE, $S$ and GIBON, V (2007). Comparative analysis of triacylglycerol composition, melting properties and polymorphic behavior of palm oil and fractions. Eur. J. Lipid Sci. Technol., 109: 359-372.

CHO, S-W and RHEE, J-S (1993). Immobilization of lipase for effective interesterification of fats and oils in organic solvent. Biotechnology and Bioengineering Vol. 41: 204-210.

CHONG, C N; HOH, Y M and WANG, C W (1992). Fractionation procedures for obtaining cocoa butterlike fat from enzymatically interesterified palm olein. J. Amer. Oil. Chem. Soc. Vol. 69 (2): 137-140. 
DE CLERCQ, N; DANTHINE, S; NGUYEN, M T; GIBON, V and DEWETTINCK, K (2012). Enzymatic interesterification of palm oil and fractions: Monitoring the degree of interesterification using different methods. J. Amer. Oil. Chem. Soc. Vol. 89: 219-229.

DIJKSTRA, A J (2015). Interesterification, chemical or enzymatic catalysis. Lipid Technology, 27: 134-136.

ESTEBAN, L; JIMENEZ, M J; GONZALEZ, P A; MARTIN, L and ROBLES, A (2011). Production of structured triacylglycerols rich in palmitic acid at $s n-2$ position and oleic acid at $s n-1,3$ positions as human milk fat substitutes by enzymatic acidolysis. Biochemical Engineering J., 54(1): 62-69.

GHOSH, P K; SAXENA, R K; GUPTA, R; YADAV, R P and DAVIDSON, S (1996). Microbial lipases: Production and applications. Science Progress, 79 (2): 119-157.

GIBON, V (2006). Fractionation of lipids for use in food. Modifying Lipids for Use in Food. Woodhead Publishing Limited, Cambridge (UK). p. 201-229.

GIBON, V (2011). Enzymatic interesterification of oils. Lipid Technology Vol. 23 (12): 274-277.

GIBON, V; AYALA, J V; DIJCKMANS, P; MAES, J and DE GREYT, W (2009). Future prospects for palm oil refining and modifications. Innovation-Technologie Vol. 16 No. 4: 193-200.

HASAN, F; ALI SHAH, A and HAMEED, A (2006). Industrial applications of microbial lipases. Enzyme and Microbial Technology, 39: 235-251.

HOLM, H C and COWAN, D (2008). The evolution of enzymatic interesterification in the oils and fats industry. Eur. J. Lipid Sci. Technol., 110: 679-691.

IBRAHIM, O M (2013). Lipase-catalysed acidolysis of palm mid fraction oil with palmitic and stearic fatty acid mixture for production of cocoa butter equivalent. Appl. Biochem. Biotechnol., 171: 655-666.

IBRAHIM, O M (2012). Lipase-catalyzed synthesis of cocoa butter equivalent from palm olein and saturated fatty acid distillate from palm oil physical refinery. App.l Biochem. Biotechnol., 168: 1405-1415.

IQBAL, M P (2014). Trans fatty acids - A risk factor for cardiovascular disease. Pakistan J. Medical Sciences, 30: 194-197.

JAHURUL, $\mathrm{M}$ H A; ZAIDUL, I S M; NIK NORULAINI, N A; SAHENA, F; ABEDIN, M Z; MOHAMED, A and MOHD OMAR, A K (2014).
Hard cocoa butter replacers from mango seed fat and palm stearin. Food Chemistry, 154: 323-329.

JAHURUL, M H A; ZAIDUL, I S M.; NIK NORULAINI, N A; SAHENA, F; JINAP, S; AZMIR, J; SHARIF, K M and MOHD OMAR, A K (2013). Cocoa butter fats and possibilities of substitution in food products concerning cocoa varieties, alternative sources, extraction methods, composition and characteristics. J. Food Engineering, 117(4): 467-476.

KANG, J-H; LEE, S-B; SONG, S-H and LEE, K-T (2011). Cocoa butter equivalents produced by the enzymatic interesterification process and method for preparing the same. US patent, US 20110262592 A 1.

KELLENS, M; GIBON, V; HENDRIX, M and GREYT, W D (2007). Palm oil fractionation. Eur. J. Lipid Sci. Technol., 109 (4): 336-349.

KHUMALO, L W; MAJOKO, L; READ, J S and NCUBE, I (2002). Characterisation of some underutilized vegetable oils and their evaluation as starting materials for lipase-catalysed production of cocoa butter equivalents. Industrial Crops and Products, 16: 237-244.

LEE, K-T and AKOH, C C (1998). Structured lipids: synthesis and applications. Food Reviews International Vol. 14 (1): 17-34.

LIPP, M and ANKLAM, E (1998). Review of cocoa butter and alternative fats for use in chocolate. Food Chemistry, 62: 73-99.

LIPP, M; SIMONEAU, C; ULBERTH, F; ANKLAM, E; CREWS, C; PRERETON, P; GREYT, W; SCHWACK, $W$ and WIEDMAIER, C (2001). Composition of genuine cocoa butter and cocoa butter equivalents. J. Food Compos. Anal., 14: 399-408.

LIU, K J; CHANG, H M and LIU, K M (2007). Interesterification of lard and tristearin in supercritical carbon dioxide by lipase enzymatic synthesis of cocoa butter analog. Food Chem., 100: 1303-1311.

LIU, K-J; CHENG, H-M; CHANG, R-C and SHAW, J-F (1997). Synthesis of cocoa butter equivalent by lipase-catalyzed interesterification in supercritical carbon dioxide. J. Amer. Oil Chem. Soc. Vol. 74(11): 1477-1482.

MOJOVIĆ, L; ŠILER-MARINKOVIĆ, KUKIĆ, G and VUNJAK-NOVAKOVIĆ (1993). Rhizopus arrhizus lipase-catalyzed interesterification of the mid fraction of palm oil to a cocoa butter equivalent fat. Enzyme Microb. Technol. Vol. 15: 438-443. 
MOJOVIĆ, L; ŠILER-MARINKOVIĆ, KUKIĆ, G; BUGARSKI, B and VUNJAK-NOVAKOVIĆ (1994). Rhizopus arrhizus lipase-catalyzed interesterification of palm oil mid fraction in a gas-lift reactor. Enzyme Microb. Technol. Vol. 16: 159-162.

MOZAFFARIAN, D; KATAN, M B; ASCHERIO, A; STAMPFER, M J and WILLETT, W C (2006). Trans fatty acids and cardiovascular disease. N. Engl. J. Med., 354: 1601-1613.

MPOB (2009). Pocketbook of Palm Oil Uses. $6^{\text {th }}$ Edition. MPOB, Bangi. p. 3-44.

MUTIA, R; ABANG ZAIDEL, D N and MUHAMAD, I I (2016). Optimization of cocoa butter equivalent production from formulated hard palm oil midfraction and canola oil blends. J. Teknologi (Sciences $\mathcal{E}$ Engineering), 78: 127-134.

NAESSENS, L (2012). Production of Cocoa Butter Equivalent through Enzymatic Acidolysis. Master thesis, University of Ghent, Belgium. p. 12.

NAIK, B and KUMAR, V (2014). Cocoa butter and its alternatives - A review. J. Bioresource Engineering and Technology, 2(1): 1-11.

NAZARUDDIN, R; NURUL ZAKIYANI, S and MAMOT, S (2011). The effect of enzymatic alcoholysis on the physicochemical properties of commercial cocoa butter substitutes. Pakistan J. Nutrition, 10 (8): 718-723.

NG, W-K and GIBON, V (2010). Palm oil and saturated fatty acid-rich vegetable oils. Fish Oil Replacement and Alternative Lipid Sources in Aqua Culture Feeds. CRC Press. p. 100-127.

NOOR LIDA, H M D; SUNDRAM, K; SIEW, W L; AMINAH, A and MAMOT, S (2002). TAG composition and solid fat content of palm oil, sunflower oil and palm kernel olein blends before and after chemical interesterification. J. Amer. Oil Chem. Soc. Vol. 79 (11): 1137-1144.

NORAZURA AILA, M H and NOORLIDA, H M D (2017). Usage of palm oil, palm kernel oil and their fractions as confectionery fats. J. Palm Oil Res. Vol. 29 (3): $301-310$.

OZAN, N C; SIBEL, F; BOLESLAW, $\mathrm{K}$ and FAHRETTIN, G (2008). Synthesis of cocoa butter triacylglycerols using a model acidolysis system. Grasas Y. Aceitas Vol. 59 (4): 316-320.

PANCHECO, C; CRAPISTE, G H and CARRIN, M E (2010). Lipase-catalyzed acidolysis of sunflower oil: Kinetic behavior. J. Food Engineering, 98 (4): 492-497.
PINYAPONG, P and PHUTRAKUL, S (2009). Synthesis of cocoa butter equivalent from palm oil by Carica papaya lipase-catalyzed interesterification. Chiang Mai J. Sci., 36 (3): 259-368.

PRSYBYLSKI, P; MAG, T; ESKIN, N A $\mathrm{M}$ and MCDONALD, B E (2005). Canola oil. Bailey's Industrial Oil and Fat Products. Vol. 6. London: John Wiley and Sons Inc.

SELLAPPAN, S and AKOH, C C (2000). Enzymatic acidolysis of tristearin with lauric and oleic acids to produce coating lipids. J. Amer. Oil Chem. Soc. Vol. 77 (11): 1127-1134.

SHUKLA, V K L (1995). Cocoa butter properties and quality. Lipid Technology, 7: 54-57.

SIVARUBY, K (2013). Effectiveness of Palm Oil Based Solid Fractions as Structural Fat in Fat Blends with Reduced Saturated Fatty Acids for Margarines and Spreads. Ph.D thesis. University of Nottingham Malaysia Campus.

SOEKOPITOJO, S; HARIYADI, $\mathrm{P}$ and ANDARWULAN, N (2009). Enzymatic interesterification of palm oil midfraction blends for the production of cocoa butter equivalents. As. J. Food Ag-Ind., 2(04): 807-816.

SONWAI, S; KAPHUEAKNGAM, P and FLOOD, A (2014). Blending of mango kernel fat and palm oil mid-fraction to obtain cocoa butter equivalent. $J$. Food Science and Technology, 51: 2357-2369.

TALBOT, G (1999). Vegetables fats. Industrial Chocolate Manufacture and Uses. $3^{\text {rd }}$ Edition, Blackwell Science, London. p. 307-322.

TALBOT, G (2007). Formulation and production of confectionery fats. Paper presented at the OFI Middle East 2007 Conference and Exhibition.

TCHOBO, F P; PIOMBO, G; PINA, M; SOUMANOU, $M \mathrm{M}$; VILLENEUVE, $\mathrm{P}$ and SOHOUNHLOUE, D C K (2009). Enzymatic synthesis of cocoa butter equivalent through transesterification of Pentadesma Butyracea butter. J. Food Lipids, 16: 605-617.

TIMMS, R E (2003). Properties, production and application. Confectionery Fats Handbook. The Oily Press. p. 229-325.

UNDURRAGA, D; MARKOVITS, A and ERAZO, S (2001). Cocoa butter equivalent through enzymatic interesterification of palm oil midfraction. Process Biochemistry, 36: 933-939.

VILLENEUVE, P; SHARBEK, A; PINA, M G J and FOGLIA, T A (1997). Catalytic behavior of Carica 
papaya latex in transesterification reactions. Biotech. Tech., 11: 637-639.

WASSELL, P and YOUNG, N W G (2007). Food applications of trans fatty acid substitutes. International J. Food Science and Technology, 42: 503-517.

WU, H-C and DENG, J (2005). Cocoa butter equivalent produced by enzymatic interesterification of palm oil mid fraction in solvent free system through orthogogal tests. Sichuan Food and Fermentation 2005-4. http://en.cnki.com.cn/ Article_en/CJFDTOTAL-SKSF200504007.htm.

XU, X (2000a). Production of specific-structured triacylglycerols by lipase-catalyzed reactions: A review. Eur. J. Lipid Sci. Technol., 102: 287-303.

XU, X (2000b). Modification of oils and fats by lipase-catalysed interesterification: Aspects of process engineering. Enzymes in Lipid Modification. Wiley-VCH Verlag GmbH \& Co. KGaA. p. 190-218.

XU, X (2003). Engineering of enzymatic reactions and reactors for lipid modification and synthesis. Eur. J. Lipid Sci. Technol., 105: 289-304.

XU, X; BALCHEN, S; HØY, C-E and ADLER-NISSEN, J (1998). Pilot batch production of specific-structured lipids by lipase-catalyzed interesterification: preliminary study on incorporation and acyl migration. J. Amer. Oil Chem. Soc. Vol. 75 (1998): 301308.

YOUNG, F; POOT, C; BIERNOTH, E; KROG, $\mathrm{N}$; DAVIDSON, $\mathrm{N}$ and GUNSTONE, F (1994). Processing of fats and oils. The Lipid Handbook. $2^{\text {nd }}$ Edition. Chapman \& Hall, New York, US. p. 277. 